\title{
FRAGMENTACIÓN SOCIO-ESPACIAL, INMIGRACIÓN EUROPEA Y DISCURSOS POLÍTICOS EN LA PROVINCIA DE ALICANTE
}

\author{
Alejandro Mantecón ${ }^{1}$ \\ Joan Carles Membrado ${ }^{2}$ \\ Raquel Huete ${ }^{1}$ \\ ${ }^{1}$ Departamento de Sociología I. Universidad de Alicante \\ ${ }^{2}$ Departamento de Geografía. Universitat de València \\ alejandro.mantecon@ua.es ; joan.membrado@uv.es ; r.huete@ua.es
}

\section{RESUMEN}

La construcción de urbanizaciones en las periferias de los municipios bajo el pretexto del desarrollo turístico ha transformado la configuración territorial de multitud de poblaciones en las regiones mediterráneas españolas. El objetivo de este trabajo es analizar los discursos que los políticos con responsabilidades directas en los respectivos ayuntamientos producen a la hora de explicar las interrelaciones creadas entre los procesos de fragmentación socioespacial fraguados en el periodo de expansión, el incremento de la inmigración europea procedente de países con un PIB per cápita mayor que el de España y los efectos ocasionados por la crisis económica iniciada entre 2007 y 2008.

Palabras clave: Alicante, crisis, migraciones, urbanismo expansivo, viviendas secundarias.

\section{ABSTRACT}

Urban sprawl development on the outskirts of the towns -under the pretext of residential tourism growth- has altered the territorial configuration of many towns in the Spanish Mediterranean regions. This paper's aim is to analyse the discourse that politicians -with direct responsibilities in some towns of the province of Alicante- produce in order to explain the interrelation existing between the processes of socio-spatial fragmentation -generated

Fecha de recepción: octubre 2014.

Fecha de aceptación: junio 2015. 
during the housing boom expansion-, the increase of the European immigrants coming from countries with a GDP per capita higher than Spain, and the effects caused by the economic crisis that started in 2007-2008.

Keywords: Alicante, crisis, migrations, urban sprawl, second homes.

\section{INTRODUCCIÓN}

La intensa actividad constructora que precedió al estallido de la gran crisis económica iniciada entre 2007 y 2008 transformó la estructura urbana y social de cientos de municipios localizados en las regiones mediterráneas españolas. Específicamente, en la provincia de Alicante resulta llamativo cómo los flujos turístico-residenciales y la inmigración de ciudadanos europeos procedentes de países con una renta per cápita más alta que la española se adaptaron a la oferta inmobiliaria generada por la masiva producción de viviendas edificadas en las periferias de los centros urbanos tradicionales, en un principio destinadas a un uso no principal (Membrado, 2013, 2014). Trabajos como los llevados a cabo por Huete (2009), Casado (2006) o Rodríguez, Lardiés y Rodríguez (2010), aclaran que dos de los rasgos más característicos de estos flujos de movilidad residencial hacia las regiones mediterráneas, y particularmente hacia la provincia de Alicante, son: primero, el hecho de estar protagonizados por personas que, en su mayoría, se hallan jubiladas o en edades próximas a las de jubilación; y, segundo, su mayoritaria procedencia de países europeos con un PIB per cápita superior al de España. A este respecto, se aclara que aquí se ha trabajado a partir de la Estadística del Padrón Continuo del INE por secciones censales, pues es la fuente de datos que mejor se ajusta para identificar espacios urbanos en los que existen concentraciones de población por nacionalidades residiendo dentro de un mismo municipio. Igualmente, no se pretende demostrar que todas las personas provenientes de países europeos con un PIB per cápita más alto que el español sean necesariamente personas ricas o más ricas que un español medio. En este sentido, se admite que ésta podría ser percibida como una limitación metodológica del esta investigación. De hecho, estudios como los de O’Reilly (2007) o Huete, Mantecón y Estévez (2013) prueban que, si bien, constituyen una minoría en términos relativos, sí que existen grupos cuantitativamente significativos de residentes extranjeros asentados en las regiones mediterráneas, oriundos de países europeos con un PIB per cápita más alto que el español, inmersos en dinámicas de empobrecimiento e, incluso, en situaciones que lindan con la exclusión social. En todo caso, y hecha esta aclaración, se advierte que a lo largo del texto se utilizan indistintamente y de modo equivalente expresiones como «extranjeros procedentes de la Europa más rica», «extranjeros ricos»o «personas procedentes de países europeos con un PIB per cápita más alto que el de España».

El modo de producción que se sustenta en el binomio construcción-ocio halla su origen en la provincia de Alicante durante los años sesenta, y sobre todo en la década de 1970, cuando se ocupan grandes espacios en los pueblos costeros justificando la necesidad de explotar turísticamente las playas. En los ochenta, el proceso se extiende a municipios distantes de la costa entre 5 y 20 kilómetros, aprovechando la fuerte demanda y el menor coste del suelo para, a finales de los noventa, alcanzar a las poblaciones del interior debido al precio del suelo aún más bajo y a la pérdida de calidad motivada por la saturación urbanística y la degradación ambiental de los municipios de primera y segunda línea (Huete, 2009). 
Así pues, si la transición a la democracia favoreció la confluencia de la economía española con las dinámicas neoliberales del capitalismo internacional, éstas solamente amplificaron unas lógicas de actuación que hunden sus raíces en el franquismo. Ya en 1972 Rafael Nasarre escribía: «a lo largo de más de una década, España ha contemplado cómo no solo sus núcleos tradicionales, sus ciudades de siempre, han visto aumentar su superficie urbana e incrementado sus servicios de infraestructura, sino que, separados de aquellos, fuera de sus zonas de ensanche, han ido apareciendo nuevos núcleos o urbanizaciones particulares que no tienen ningún nexo de unión con el núcleo principal, como no sea el de pertenecer al mismo municipio y el de estar bajo la jurisdicción del mismo Ayuntamiento. Tales núcleos han aparecido principalmente en zonas de nuestro litoral, calificadas -sin duda, a consecuencia de ello- de turísticas» (1972: 24). En 1979 Francisco Jurdao resumía nueve características de las nuevas urbanizaciones: 1) se trata de nuevos núcleos urbanos, 2) no están conectados con el núcleo tradicional, 3) el único lazo que une el nuevo espacio con el viejo es estar bajo el control administrativo del mismo Ayuntamiento, 4) la mayoría de los habitantes de las nuevas urbanizaciones son propietarios de los inmuebles, 5) el mayor porcentaje de propietarios es extranjero, 6) es una población heterogénea y no permanente, 7) a lo que se une el hecho de existir frecuentes transacciones de propiedad, 8) todo ello dificulta la vida comunitaria, 9) finalmente, la renta de los habitantes en los nuevos núcleos es más alta que la del resto de residentes en el término municipal.

Por lo tanto, la fragmentación socio-espacial que han experimentado tantas localidades de las provincias mediterráneas a causa de la construcción de urbanizaciones y diseminados de viviendas en las periferias municipales tiene como principal novedad desde la década de 1990 la intensidad adquirida y, en concreto, su expansión a los municipios alejados de la costa. Cuando aquí se habla de fragmentación socio-espacial se alude de modo genérico a la interrupción de la continuidad entre viejos y nuevos desarrollos urbanos, dejando vacíos entre medio (Muñiz et al., 2006).

\section{DINÁMICA DE LA FRAGMENTACIÓN EN LA PROVINCIA DE ALICANTE}

Investigaciones previas han explicado las dinámicas que intervienen en la producción de estas nuevas estructuras urbanas y los efectos que provocan en Alicante, la provincia española en la que se han identificado más nítidamente poblaciones donde el distanciamiento entre los ciudadanos originarios de países europeos con un PIB per cápita más alto que el de España y el resto de residentes revela la existencia de dos órdenes sociales diferentes (Huete y Mantecón, 2011, 2012; Mantecón et al., 2009). Los estudios citados documentan un proceso de fragmentación espacial ligado a otro de fragmentación social. Este último se articularía mediante al menos tres tendencias: a) una dualización relativa a la función socioeconómica del espacio, que es orientado mayoritariamente hacia las funciones de ocio o hacia las funciones productivas, b) una diferenciación sociodemográfica que cristaliza en la sobrerepresentación de determinados grupos de edad en cada uno de los espacios considerados, y c) una desigual distribución de las personas de determinadas nacionalidades, cuya manifestación empírica más ilustrativa se observa en el «encapsulamiento» de grupos de, principalmente, ciudadanos británicos y alemanes -con una presencia predominante de mayores de 55 años- en las urbanizaciones construidas en las periferias municipales. Si el desconocimiento del idioma suele esgrimirse por los responsables políticos como el argumento más recurrente 
para zanjar la discusión relativa a los problemas de interacción entre los residentes españoles y los de otros países europeos, los estudios realizados indican cómo esta dificultad es únicamente la parte más visible de un iceberg que, en realidad, oculta un entramado de relaciones entre dimensiones socio-espaciales, políticas, culturales y económicas. Ese entramado acaba por configurar un sistema social que, más allá de las cuestiones idiomáticas, complica el establecimiento de vínculos significativos entre la población española y los otros residentes europeos, propiciando más bien dinámicas que promueven la separación.

Igualmente, tal y como han documentado Huete y Mantecón (2011), el núcleo urbano tradicional es habitado mayoritariamente por españoles mientras que en las urbanizaciones residen principalmente extranjeros procedentes de países con un PIB per cápita más alto que el de España. Las secciones censales correspondientes a los viejos cascos urbanos muestran unos datos sensiblemente diferentes a las que corresponden con las nuevas macrourbanizaciones periféricas. En los primeros, el porcentaje de extranjeros no suele superar el 5\%, o como mucho se encuentra entre el 5 y el $25 \%$. En las segundas, el porcentaje de extranjeros procedentes de la «Europa más rica» se encuentra entre el 25 y el $50 \%$ en algunos municipios sobre todo del interior; se halla entre el 50 y el $75 \%$ en muchos municipios del prelitoral; y supera el $75 \%$ en la mayoría de municipios del litoral. Para contextualizar estos datos se ha de considerar que, según la Estadística del Padrón Continuo, a 1 de enero de 2012, había 472.610 ciudadanos extranjeros empadronados en la provincia de Alicante (sobre una población total de 1.943.910 habitantes). El 49\% de los extranjeros procedía de países con un PIB per cápita más alto que el español, entre ellos sobresalía el contingente británico, con 127.927 efectivos seguido de Alemania que aportaba 35.016 nacionales.

\section{OBJETIVO Y METODOLOGÍA}

El objetivo de este trabajo es analizar los discursos que los políticos con responsabilidades directas en los respectivos ayuntamientos producen a la hora de explicar la particular configuración territorial, caracterizada por la fragmentación socio-espacial, de los municipios en los que gobiernan.

La pertinencia de estudiar los discursos de los políticos en el poder local viene dada por el hecho de constituirse, junto a los empresarios promotores, en la principal fuente de argumentos legitimadores del urbanismo expansivo - presentado habitualmente bajo la etiqueta eufemística «turismo residencial»- en la provincia de Alicante durante los años anteriores al estallido de la burbuja inmobiliaria (Mantecón, 2008a,b). Así, los políticos con responsabilidad en el gobierno municipal se constituyeron como un actor social clave desde que decidieron especializarse en atraer inversiones privadas y en gestionar según criterios de aparente eficiencia empresarial los recursos físicos y humanos acumulados en el territorio sobre el que ejercen influencia. Amparados por el manto ideológico de la competitividad y esgrimiendo el desarrollo turístico como excusa que justificaba la expansión de la economía inmobiliaria (Mantecón, 2010), los políticos municipales aprovecharon su creciente poder en materia urbanística para convertir el suelo en una combinación de oportunidades con las que hacer negocio. A la vez, como ha explicado Fernando Vera (2005), la recaudación sobre el parque de unidades urbanas se tornaría en la vía de ingresos más sustancial para las haciendas municipales. 
La apuesta por alimentar un tipo de crecimiento económico sustentado en la inversión inmobiliaria se ajustó bien a la expansión del sistema turístico-residencial dentro y fuera de España (Salvà, 2011). Al respecto, la multiplicación de las regiones que en las últimas décadas han tratado de posicionarse como destinos turísticos aumentó la competencia y animó a las instituciones con capacidad de decisión a incrementar la intensidad con la que mercantilizaban los espacios. De tal forma, las autoridades políticas locales dieron prioridad a los requerimientos de la industria inmobiliaria, por ejemplo promoviendo cambios en la legislación urbanística, pervirtiendo los principios supuestamente racionales de los planes generales de ordenación urbana, financiando la construcción de infraestructuras que servían en primer lugar a intereses particulares o tolerando la expansión de amplios sectores de economía informal (Díaz y Lourés, 2008; Mazón, 2006; Navarro et al., 2000; Requejo, 2007; Rullán, 2012; Vera, 2005).

El análisis que se presenta en las siguientes páginas tiene el aliciente añadido de llevarse a cabo en un contexto de crisis económica, vinculado evidentemente al colapso del sector del ladrillo. En este sentido, resulta de especial interés entender de qué modo un actor social tan significativo como el que conforman los políticos en el poder local interpreta las interrelaciones creadas entre, por un lado, los procesos de fragmentación socio-espacial fraguados en el periodo de expansión y, por otro, los efectos ocasionados por la crisis económica.

Una vez identificada la provincia de Alicante como la región española en la que se advierte una presencia más numerosa y una manifestación más intensa de los procesos de fragmentación apuntados (Huete y Mantecón, 2011; Martí y Nolasco, 2012), para llevar a cabo la investigación se seleccionaron los municipios en los que se registraba un porcentaje de población extranjera empadronada superior al 25\% de la población total. La información relativa al porcentaje de extranjeros residentes en cada municipio y procedentes de países europeos con un PIB per cápita más alto que el español se basa en los datos de la Estadística del Padrón Continuo del INE por secciones censales para 2012. A continuación se dividió a los 25 municipios que reunían el requisito indicado entre los que registraban porcentajes mayores o menores del 50\%. Finalmente, fueron clasificados según su localización en el litoral (a una distancia inferior a 5 kilómetros de la costa), el prelitoral (los ubicados a entre 5 y 10 kilómetros de la costa) o el interior (a más de 10 kilómetros). El procedimiento para clasificar a un municipio en una u otra categoría se realizó desfasando la línea de costa hasta tocar uno de los vértices del polígono que forma el límite del municipio, obteniendo así la mínima distancia entre el municipio y la costa y contrastando los datos mediante acotaciones. La base cartográfica es del Instituto Geográfico Nacional a escala 1:200.000 en formato shapefile tratado mediante un sistema de información geográfica (SIG). Esto ha supuesto el uso del sistema geodésico de referencia ETRS89 y coordenadas geográficas de longitud y latitud (sin proyección cartográfica). La disposición final de los 25 municipios seleccionados se recoge en el Cuadro 1. Este cuadro resulta útil para comprobar cómo los 25 municipios responden a una variedad de situaciones relativas tanto a su localización en el territorio como a su composición sociodemográfica.

Con el fin de ilustrar más detalladamente la naturaleza del proceso de fragmentación explicado, se ha seleccionado un ejemplo representativo de cada una de las tres columnas del cuadro (litoral, prelitoral e interior), plasmando en tres mapas los datos de empadronamiento de la población extranjera procedente de países europeos con PIB per cápita superior al español (ver apartado IV.4.). En estos mapas no solo se muestra el porcentaje de extranjeros procedentes de «países 
ricos», sino también la distribución de las urbanizaciones. Se han elaborado a partir de una base cartográfica que corresponde con el mapa de sombras del Institut Cartogràfic Valencià, a partir del programa informático ArcGIS (ESRI), usando el sistema geodésico de referencia ETRS89. Sobre esta base se han dibujado los cascos urbanos (correspondientes a una o varias secciones censales) y las urbanizaciones periféricas (correspondientes normalmente a una sola sección censal). Tomando los porcentajes de población extranjera de cada sección censal se han definido las tramas a partir de líneas diagonales, cuya mayor o menor densidad indica mayor o menor proporción de extranjeros procedentes de países con un PIB per cápita más alto que el de España.

\section{Cuadro 1}

PORCENTAJE DE POBLACIÓN EXTRANJERA EMPADRONADA EN 2012

\begin{tabular}{|c|c|c|c|}
\hline & Litoral & Prelitoral & Interior \\
\hline $\begin{array}{l}\text { Municipios con una } \\
\text { población extranjera } \\
\text { entre un } 25 \% \text { y un } \\
50 \%\end{array}$ & $\begin{array}{l}\text { - Busot } \\
\text { - Finestrat } \\
\text { - Teulada-Moraira } \\
\text { - l'Alfàs del Pi }\end{array}$ & $\begin{array}{l}\text { - La Nucia } \\
\text { - San Miguel de Salinas } \\
\text { - Bolulla } \\
\text { - Tàrbena }\end{array}$ & $\begin{array}{l}\text { - Millena } \\
\text { - Beniardá } \\
\text { - La Romana } \\
\text { - Xixona }\end{array}$ \\
\hline $\begin{array}{l}\text { Municipios con una } \\
\text { población extranjera } \\
\text { igual o superior al } \\
50 \%\end{array}$ & $\begin{array}{l}\text { - Calp } \\
\text { - San Fulgencio } \\
\text { - Benijófar } \\
\text { - Benitatxell } \\
\text { - Rojales }\end{array}$ & $\begin{array}{l}\text { - Llíber } \\
\text { - Algorfa } \\
\text { - Daya Vieja } \\
\text { - Benidoleig } \\
\text { - Alcalalí }\end{array}$ & $\begin{array}{l}- \text { Castalla } \\
\text { - Hondón de las } \\
\quad \text { Nieves } \\
\text { - Hondón de los } \\
\text { Frailes }\end{array}$ \\
\hline
\end{tabular}

Fuente: elaboración propia a partir de datos de la Estadística del Padrón Continuo a 1 de enero de 2012 (INE, 2012).

El análisis de los discursos de las élites políticas locales se realizó desde un enfoque metodológico cualitativo sustentado en la aplicación de entrevistas en profundidad a un alcalde o un concejal del partido en el poder de cada uno de los 25 municipios seleccionados. A partir de la experiencia de investigaciones cualitativas anteriores (Mantecón, 2008a), se consideró que una entrevista a un responsable en el poder local de cada uno de los ayuntamientos resultaría suficiente para recoger el discurso que representa los principios ideológicos del partido en el poder. Asimismo, se asumió que un mayor número de entrevistas a miembros del mismo partido en el mismo municipio ofrecería una información esencialmente redundante. Las entrevistas tuvieron una duración aproximada de entre 45 y 90 minutos y se realizaron con la ayuda de un guión semi-estructurado que recogía preguntas abiertas relativas a la valoración de aspectos socioeconómicos y culturales asociados a la presencia de los extranjeros europeos residentes en el municipio y procedentes de países con un PIB per cápita más alto que el de España. Las preguntas concretas que conformaban el guión son las siguientes:

- Según mis datos, es a partir de X (varía según el municipio) cuando aumentó el número de alemanes/ingleses/noruegos/suizos...europeos ¿Podría describirme cuál era la situación del municipio antes de que se instalaran estos nuevos vecinos?

- ¿Por qué razones cree usted que vinieron a vivir aquí?

- ¿Podría hablarme de los cambios urbanísticos que experimentó el municipio con la llegada de estos nuevos vecinos? 
- ¿Qué valoración puede hacerme de esos cambios urbanos? ¿Han resultado positivos, negativos, neutros para el municipio?

- ¿Cuál es el perfil sociológico de los residentes europeos de la localidad? ¿Son personas con recursos económicos mayores o menores que los de la población española, su nivel cultural es mayor o menor...?

- ¿Cree que existen diferencias significativas entre la vida que llevan los vecinos que residen en el pueblo tradicional respecto a los que viven en las nuevas urbanizaciones? ¿En qué consisten?

- ¿Existe una relación fluida entre la población foránea y la local o viven un poco en «mundos aparte»? Háblenos de este asunto.

- ¿Se llevan a cabo acciones desde el ayuntamiento para facilitar la relación entre los vecinos de las urbanizaciones y los del centro? Háblenos de ellas.

- ¿Qué dificultades considera que se encuentran para que las iniciativas municipales orientadas a favorecer la interacción entre los distintos grupos nacionales tengan éxito?

- ¿Qué efectos han tenido las medidas que se han llevado a cabo hasta ahora?

- Los europeos residentes ¿qué tal viven aquí? ¿Sabe si tienen algún problema significativo?

- ¿Cómo perciben los residentes españoles la presencia de estos nuevos vecinos?

- ¿Cómo valora usted el hecho de que los extranjeros europeos vivan en urbanizaciones alejadas del casco urbano tradicional? ¿Podría indicarme algún problema o cuestión crítica al respecto?

- En líneas generales, ¿podría hacerme un balance sobre la influencia que ha tenido la llegada de estas personas en el desarrollo social y económico del municipio?

El trabajo de campo se llevó a cabo entre los meses de julio y octubre de 2012. Se entrevistó a 19 concejales, 2 tenientes de alcalde y 4 alcaldes. 16 de los entrevistados representaban al Partido Popular, 7 al PSOE y 2 a la coalición Bloc-Compromís.

Después de transcribir íntegramente la información recogida, se emprendió un análisis -podría decirse «temático»- mediante el cual se generaron familias de códigos (infraestructuras, salud, clima, integración, urbanizaciones, idioma, etc.). Seguidamente, se reclasificó el material reunido elaborando notas, identificando posiciones comunes, asociando ideas y descubriendo líneas argumentales. Esta parte del trabajo, de descomposición y reconfiguración de los textos, se repitió sistemáticamente hasta que fue posible reconocer ciertos «patrones de regularidad», utilizando la expresión de Fernando Conde (2009: 106). Esta forma de proceder, como señala Conde, representa la línea mayoritaria del análisis cualitativo y, aunque obviamente tiene sus limitaciones, aquí ha resultado útil para trabar un argumento explicativo a partir de los datos recopilados.

\section{ANÁLISIS CUALITATIVO DE LOS DISCURSOS POLÍTICOS}

El argumento se organiza en cinco apartados en los que se estudia la percepción de los políticos respecto a la fragmentación socio-espacial que caracteriza los municipios en los que gobiernan en el marco de una valoración más amplia sobre los efectos del proceso migratorio-residencial con el que esa fragmentación se articula. De este modo se pretende un enfoque más comprensivo. 


\section{IV.1. Esquema general sobre la percepción del proceso de interacción entre locales y residen- tes extranjeros}

El análisis de los discursos recopilados mediante la aplicación de las entrevistas en profundidad permite observar el reconocimiento por parte de los políticos de una serie de factores generales que son considerados positivos o negativos dentro de cada una de las fases (la anterior a la crisis económica y la actual) a propósito de las relaciones entre los residentes extranjeros y los locales. De forma muy sintética, en los cuadros siguientes se ordenan esos factores. Se consigue así una primera panorámica de la valoración por parte de los políticos para, en los apartados siguientes, profundizar en algunos aspectos que resultan de especial interés de acuerdo con el objetivo apuntado.

Cuadro 2

VALORACIÓN DE FACTORES EN RELACIÓN CON LOS RESIDENTES EXTRANJEROS

\begin{tabular}{|c|c|c|}
\hline $\begin{array}{l}\text { Se interpreta para los } \\
\text { residentes extranjeros... }\end{array}$ & $\begin{array}{l}\text {...de modo predominantemente } \\
\text { positivo }\end{array}$ & $\begin{array}{l}\text {...de modo predominantemente } \\
\text { negativo }\end{array}$ \\
\hline A la llegada de los residentes & $\begin{array}{l}\text { El clima y la tranquilidad, } \\
\text { tanto en la costa como en el } \\
\text { interior. }\end{array}$ & $\begin{array}{l}\text { La cultura laxa y poco } \\
\text { exigente. Las carencias de } \\
\text { idioma. }\end{array}$ \\
\hline $\begin{array}{l}\text { En la interacción social y la } \\
\text { vida cotidiana }\end{array}$ & $\begin{array}{l}\text { Asociacionismo, actividades } \\
\text { culturales, atención } \\
\text { administrativa, integración, } \\
\text { aprendizaje del idioma, } \\
\text { beneficios de negocios. La } \\
\text { tranquilidad. }\end{array}$ & $\begin{array}{l}\text { Problemas de comunicación, } \\
\text { sobre todo en servicios } \\
\text { esenciales como salud. } \\
\text { Nuevos impuestos } \\
\text { y requerimientos } \\
\text { administrativos. Aislamiento y } \\
\text { soledad en la vejez. }\end{array}$ \\
\hline \multicolumn{3}{|c|}{ Proceso interviniente: crisis económica y envejecimiento de los residentes extranjeros } \\
\hline $\begin{array}{l}\text { Salen de la urbanización } \\
\text { (hacia el centro del pueblo) }\end{array}$ & $\begin{array}{l}\text { Aumenta la proximidad a } \\
\text { servicios básicos (sobre todo } \\
\text { de salud), integración social. }\end{array}$ & No se mencionan. \\
\hline $\begin{array}{l}\text { Salen de la localidad (hacia } \\
\text { su país) }\end{array}$ & $\begin{array}{l}\text { Acogida en la seguridad } \\
\text { redescubierta de su viejo } \\
\text { hogar. En su caso, trabajo o } \\
\text { red familiar. }\end{array}$ & $\begin{array}{l}\text { Salida de su «hogar } \\
\text { construido». Sentimiento de } \\
\text { fracaso de su proyecto vital en } \\
\text { España. }\end{array}$ \\
\hline
\end{tabular}

Cuadro 3

VALORACIÓN DE FACTORES EN RELACIÓN CON LOS RESIDENTES LOCALES

\begin{tabular}{|l|l|l|}
\hline $\begin{array}{l}\text { Se interpreta para los } \\
\text { locales... }\end{array}$ & $\begin{array}{l}\text {..de modo predominantemente } \\
\text { positivo }\end{array}$ & $\begin{array}{l}\text {..de modo predominantemente } \\
\text { negativo }\end{array}$ \\
\hline A la llegada de los residentes & $\begin{array}{l}\text { Generación de empleo, venta } \\
\text { de terrenos y beneficios }\end{array}$ & $\begin{array}{l}\text { Saturación. Sensación de } \\
\text { pérdida de control sobre la } \\
\text { localidad de nacimiento. }\end{array}$ \\
\hline
\end{tabular}




\begin{tabular}{|l|l|l|}
\hline $\begin{array}{l}\text { En la interacción social y la } \\
\text { vida cotidiana }\end{array}$ & $\begin{array}{l}\text { Beneficio económico, apertura } \\
\text { cultural, integración, nuevas } \\
\text { actividades y ocio. }\end{array}$ & $\begin{array}{l}\text { Incompatibilidad cultural } \\
\text { (trato a los animales, } \\
\text { limpieza...), tensión por la } \\
\text { fragmentación, dependencia } \\
\text { económica, frustración en la } \\
\text { comunicación, saturación de } \\
\text { servicios... }\end{array}$ \\
\hline Proceso interviniente: crisis económica y envejecimiento de los residentes extranjeros \\
\hline $\begin{array}{l}\text { Salen de la urbanización } \\
\text { (hacia el centro del pueblo) }\end{array}$ & $\begin{array}{l}\text { Integración social, nuevas } \\
\text { relaciones. }\end{array}$ & No hay evidencias. \\
\hline $\begin{array}{l}\text { Salen de la localidad (hacia } \\
\text { su país) }\end{array}$ & $\begin{array}{l}\text { «Vuelta a la tranquilidad» (en } \\
\text { algunos casos). }\end{array}$ & $\begin{array}{l}\text { Pérdida de dinero, destrucción } \\
\text { de empleos. }\end{array}$ \\
\hline
\end{tabular}

Cuadro 4

VALORACIÓN DE FACTORES EN RELACIÓN CON LA LOCALIDAD

\begin{tabular}{|c|c|c|}
\hline $\begin{array}{l}\text { Se interpreta para la } \\
\text { localidad... }\end{array}$ & $\begin{array}{l}\text {...de modo predominantemente } \\
\text { positivo }\end{array}$ & $\begin{array}{l}\text {...de modo predominantemente } \\
\text { negativo }\end{array}$ \\
\hline A la llegada de los residentes & $\begin{array}{l}\text { Desarrollo urbano. } \\
\text { Desarrollo económico. } \\
\text { Nuevas ayudas de la } \\
\text { administración pública. }\end{array}$ & $\begin{array}{l}\text { Explosión urbana y } \\
\text { construcción desarticulada de } \\
\text { urbanizaciones. }\end{array}$ \\
\hline $\begin{array}{l}\text { En la interacción social y la } \\
\text { vida cotidiana }\end{array}$ & $\begin{array}{l}\text { Mayores ingresos por } \\
\text { incremento de la población. } \\
\text { Desarrollo socioeconómico. }\end{array}$ & $\begin{array}{l}\text { Crecimiento de los gastos en } \\
\text { infraestructuras y servicios, } \\
\text { cursos..., necesidad de atender } \\
\text { demandas de los residentes. }\end{array}$ \\
\hline \multicolumn{3}{|c|}{ Proceso interviniente: crisis económica y envejecimiento de los residentes extranjeros } \\
\hline $\begin{array}{l}\text { Salen de la urbanización } \\
\text { (hacia el centro del pueblo) }\end{array}$ & $\begin{array}{l}\text { Reestructuración urbana, } \\
\text { reducción de exigencias de } \\
\text { infraestructuras, servicios y } \\
\text { del gasto. Mejora de negocios } \\
\text { ubicados en el núcleo urbano } \\
\text { tradicional. }\end{array}$ & No hay evidencias. \\
\hline $\begin{array}{l}\text { Salen de la localidad (hacia } \\
\text { su país) }\end{array}$ & $\begin{array}{l}\text { Reducción de exigencias de } \\
\text { infraestructuras, servicios y } \\
\text { del gasto. }\end{array}$ & $\begin{array}{l}\text { Pérdida de población y de } \\
\text { apoyos gubernamentales, } \\
\text { desestructuración urbana por } \\
\text { abandono de urbanizaciones. } \\
\text { En consecuencia, pérdida } \\
\text { del atractivo general de la } \\
\text { localidad. }\end{array}$ \\
\hline
\end{tabular}

\section{IV.2. Actitudes hacia la llegada de residentes extranjeros}

El análisis identifica cuatro actitudes básicas de los políticos hacia los residentes extranjeros: a) de los llegados como «héroes»; b) de gratitud hacia los llegados; c) de «invisibilidad» de los llegados; d) de los llegados como una especie de «plaga». 
La idea de la llegada de residentes extranjeros como la salvación de la población no es una visión generalizada en las localidades de la provincia, pero puede decirse que esta actitud se observa al menos en un par de casos, pueblos pequeños en los que la tendencia era el despoblamiento hasta la llegada de los nuevos residentes. Al respecto, existe una gran asociación entre el sector productivo en el que «se movía» la vida del pueblo y la idea de que el pueblo estaba en vías de desaparición: poblaciones especializadas en la agricultura hasta que llegaron los nuevos vecinos. La segunda actitud apuntada (de gratitud) es, con mucho, la más nutrida de las cuatro. Puede advertirse más nítidamente allí donde la llegada de los extranjeros ha contribuido a una renovación del casco urbano. En estos mismos lugares se observa que los entrevistados hacen más énfasis en los procesos de integración que han tenido lugar que en las repercusiones más negativas provocadas por el proceso de fragmentación. Es decir, esta actitud se da sobre todo cuando hay una integración espacial, cuando la proliferación de las urbanizaciones corre pareja a una incorporación de residentes en el centro tradicional y, particularmente, cuando los antiguos residentes de los centros tradicionales perciben una aportación económica significativa de los nuevos residentes en el municipio. Esta actitud se generaliza tanto en poblaciones de interior como en otras más cercanas a la costa:

«Algunos viven en el casco urbano y creo que es mejor, porque están más relacionados con la gente del pueblo y el ayuntamiento [...] la comunicación entre la gente es más fuerte que si vivieran en la urbanización. Esto repercutió en la mejora total del casco urbano, muchas casas que estaban abandonadas o que no se gastaban ni como trasteros, se han comprado muchas casas y ahora están restauradas y la gente vive aquí. Hay dos bares en el pueblo, van a beberse la cerveza o van a comer, incluso vienen otros familiares o amigos que tienen en la costa y vienen a pasar el día» (Bolulla).

En La Nucía, donde se hace referencia a una significativa fragmentación socio-espacial, es evidente que la expansión acelerada de las urbanizaciones no implica un impacto negativo. Se puede vivir bien cuando la economía está siendo alimentada por los extranjeros, al margen de su interacción con la población autóctona. La percepción no es de supeditación resignada hacia el extranjero sino de igualdad:

«La política en este momento es que todos somos iguales, siendo residentes del pueblo o de las urbanizaciones, todos somos prácticamente iguales. Ya te he dicho que ahora mismo es más importante que nunca, que esta parte extranjera está ayudando en la economía. Su mayoría son pensionistas, ellos tienen sus pensiones del norte de Europa y claro aquí gastan, eso para la economía es muy importante» (La Nucia).

La tercera actitud indicada (de «invisibilidad») tiene una presencia menor que la anterior. Suele relacionarse con poblaciones muy pequeñas con una oferta comercial y de servicios valorada como insuficiente por los residentes extranjeros, que entonces buscan otros pueblos para hacer su vida cotidiana. Aquí, a diferencia de en los ejemplos anteriores, no se percibe el valor económico de los extranjeros: 
«Ni bien, ni mal, ni hay rechazo... ingleses son eso, pero no notas al pueblo... que piensen ¡ostras que no están invadiendo! no, ni mucho menos. Además como que tampoco en el pueblo sólo hay una familia que vive desde hace cuatro o cinco años, la única que vive en el pueblo, son personas mayores también. No saben ni papa de español, de nada, ni quieren saber, pero ellos están, se ajuntan, cenan... las cámaras, las fotos las no sé que... la gente no tiene... quizás otro tipo de residentes... pero a los ingleses la verdad, a los europeos... no, a los otros no te puedo decir, pero rechazo no hay por ningún lado» (Millena).

Otra posibilidad para esa indiferencia, para esa omisión de reconocimiento y de relaciones, es la que surge ante la fragmentación socio-espacial. Nótese la diferencia de actitud respecto al caso de La Nucia: allí se hablaba de que los extranjeros viven aparte, pero son reconocidos por su valor al apoyar la economía local con su consumo y pago de su parte de gastos municipales; en el caso de San Fulgencio la cosa cambia:

«Hay cierto nivel de indiferencia, no hay mucho contacto y sobre como también con el idioma, a veces digo, che chico súbete... y me responden que es que no me entiendo con la gente, que son todos ingleses. La barrera de idioma junto a la carretera como Dios manda eso hace que no haya una integración y que no haya unión» (San Fulgencio).

Finalmente, puede también reconocerse una actitud muy marginal en el discurso de los políticos en virtud de la cual la presencia de los residentes extranjeros se valoraría negativamente. El entrevistado en Benidoleig percibe incluso que hasta la economía ha podido empeorar con la llegada de los extranjeros europeos:

«Era un pueblo que en aquel entonces habían setecientos habitantes y ahora ya somos mil trescientos y tampoco se han abierto más empresas si no lo contrario. En temas de servicios ha ido perdiendo, porque la gente mayor tenía su tienda de alimentación en el pueblo y todos subsistíamos, pero empezó el boom de los extranjeros y de las grandes superficies y todo eso ha influenciado a que fueran cerrando antes sí que se vivía de eso y después ya no se podían vivir... y a nivel de servicios hasta incluso estamos algo peor» (Benidoleig).

Se subraya que el último extracto presentado se asocia a un discurso cuya presencia es anecdótica en el conjunto de las entrevistas realizadas. De hecho, coincide con uno de los dos municipios gobernados por la coalición Bloc-Compromís. En realidad, el análisis no ha hallado variaciones discursivas relevantes entre los representantes del PSOE y del PP.

\section{IV.3. Factores que han marcado la convivencia}

Las actitudes ante los residentes extranjeros dependen de la percepción acerca del modo en el que los extranjeros se han asentado en el municipio y han tratado de establecer vínculos con la población local. Ahora bien, ¿cuáles son los aspectos clave de esa vida en común? El 
análisis de las descripciones y argumentos de los entrevistados permite identificar una variedad de cuestiones relevantes que parecen haber marcado la interacción (o la falta de ésta). Seleccionando las cuestiones citadas con mayor frecuencia en las entrevistas, se observa que las dinámicas municipales han sufrido problemas variados, desde los reiterados a propósito de las dificultades idiomáticas entre nativos y visitantes, hasta las carencias en infraestructuras y servicios y el desarrollo de urbanizaciones.

Ante los problemas derivados de las carencias idiomáticas, las administraciones municipales han desplegado diferentes esfuerzos. De hecho, se trata de uno de los temas más abordados en todos municipios al hablar de las políticas locales. Así, para superar esas dificultades, se cita ampliamente por parte de diferentes ayuntamientos una estrategia común: el uso de las asociaciones de residentes extranjeros, que son percibidas como una vía especialmente efectiva para la integración y el desarrollo cultural (sobre las funciones sociopolíticas y culturales de estas asociaciones ver Haas, 2012; Huete y Mantecón, 2012 y, especialmente, Simó et al., 2005):

«Tenemos ciertos problemas de comunicación, pero solemos superarlos recurriendo a las asociaciones de vecinos sobre todo a la de Ladies Club, quienes nos facilitan muchísimo la comunicación con la población que reside en la urbanización» (Busot).

«Nunca es malo lo que se hace en determinado momento, son circunstancias y son las que habían y ahora son las que hay, hay que actuar con las circunstancias que hay... ahora esta gente participa incluso más y trabajan en asociaciones en amas de casas y tercera edad, oye no hay problema, hay que aprovechar la experiencia de estas personas... porque ahora tienes un chiquito que estudia idiomas y en vez de coger e irse de Erasmus a practicar idiomas, envíalo a Solana Gardens» (Alcalalí).

La segunda de las cuestiones valoradas en términos problemáticos para las corporaciones locales está relacionada con la demanda de infraestructuras y servicios desde las urbanizaciones construidas en las periferias municipales. Al respecto, es habitual que los entrevistados defiendan su gestión a la hora de buscar soluciones que alivien los problemas asociados a esta realidad:

«Nosotros hemos tenido muchos problemas por el tema de la prestación del servicio de agua potable que hasta hace... hasta el año pasado estaba siendo prestado por una empresa privada y el agua era agua procedente de pozos y no era agua en condiciones. Eso era un problema que era de veinte y veintidós años atrás, entonces el ayuntamiento ha sacado en concesión la gestión de ese servicio público de agua y ahora está siendo gestionado por una empresa, que es Gestagua, y hasta día de hoy los vecinos han asumido el cambio, han visto que era para mejor, a pesar de que ha subido un poco el coste del agua, pero está dentro de la normalidad, los vecinos de las urbanizaciones han visto que se les ha solucionado un problema muy importante que había y bueno pues, no he visto yo quejas más allá de lo normal. Más allá del desconocimiento de cómo se empezaba a gestionar el servicio, el agua a partir de este año, lo normal, tampoco hemos tenido ninguna queja así fuera de lo común, simple- 
mente pues... yo que sé, la inquietud que genera, cómo voy a recibir este servicio, lo qué me va a costar o dónde me he de dirigir si tengo cualquier problema con ese servicio y ya está. Ese es el principal problema que hemos tenido que gracias a Dios, ya lo hemos solucionado, es todo lo que te puedo decir» (San Miguel de Salinas).

El fragmento anterior muestra un problema recurrente: la dejadez que en algunas partes se ha producido respecto a la prestación de servicios a las urbanizaciones en comparación con los centros urbanos tradicionales.

«He oído disparates de compañeros de otros ayuntamientos, que como hay urbanizaciones desde hace bastante años, bastante pobladas, bastantes más grandes que el propio pueblo y tienen problemas de alcantarillado desde el primer momento, no tienen una buena red, las carreteras también terribles, muy mal asfaltadas y sin embargo después vas a los centros urbanos de esos pueblos y los ves impecables» (Daya Vieja).

Así, es fácil pensar que los extranjeros vinieron en ocasiones a urbanizaciones que no estaban preparadas para recibirlos, y que los problemas se han desatado cuando ellos han comenzado a exigir la inversión pública en sus zonas. Una inversión que, a juicio de los políticos, deberían haber realizado los urbanizadores.

«Suelen quejarse porque la depuradora de agua no funciona, porque la luz no llega, hay problemas de electrificación, son problemas porque el urbanizador no ha terminado las obras urbanizadoras. Aquí se produjo también, aunque eso también es otra cuestión, el hecho incomprensible que el ayuntamiento anterior concedió células de ocupación, que es el documento digamos que permite ocupar una vivienda o que reconoce administrativamente, es decir, la administración reconoce que esa vivienda está bien para estar ocupada. Que no debían de haberse dado porque no es sólo vivienda, no es sólo que la vivienda esté bien sino el entorno, toda la infraestructura esté bien, en condiciones, falta luz, falta agua, falta depuradora como mínimo» (Castalla).

«Aquí el plan general no contemplaba que los constructores tenían que dar las infraestructuras necesarias, sobre todo el alcantarillado, porque carreteras y calles y esto sí que han hecho y lo han hecho bien, las carreteras que hay sí que las tenemos, pero no había alumbrado público que es lo que ahora reclaman muchos residentes y desde luego no existe alcantarillado» (Teulada-Moraira).

Pero también se piden servicios ya demandados hace tiempo, o incluso nuevos servicios necesitados en parte porque la población ha envejecido. La cita siguiente une las dos características en la demanda:

«Pero hasta hoy poner un autobús, hace años que estamos pidiéndole aquí en Quesada, tenemos necesidades aquí en Quesada porque es muy grande. No podemos ir 
andando hasta Rojales, la gente está mayor para coger el coche. Hace años había uno pero se quitó supongo por razones económicas, ahora mismo hay mucha demanda porque la gente es más mayor, gente de 70 a 80 que era cinco años menos, era más independiente ahora mismo hay más demanda» (Rojales).

En otros casos, se incorpora al discurso el tema de la inseguridad, igualmente recurrente y problemático:

«Ellos quieren tener los mismos servicios que tenemos nosotros en el casco urbano. Otro problema volviendo a lo de antes es el idioma, claro muchos de ellos viven en las mismas urbanizaciones donde se rodean e interactúan con población extranjera, además en algunos casos, a lo mejor en una calle se da el fenómeno de casas vacías, entonces puede ser que una persona viva sola en un barrio. También exigen seguridad porque tienen miedo, pero nosotros sólo tenemos un policía local que trabaja desde las 7 de la mañana hasta las 10. En cuanto a comunicación, intentamos poner un tramo del autobús que pasara por la urbanización con su parada correspondiente, pero eso todavía está pendiente» (Hondón de las Nieves).

Ahora, en un contexto de crisis económica, la solución a los diversos problemas y demandas se complica a causa de las carencias presupuestarias que se han adueñado de las corporaciones locales. De este modo, las demandas de los residentes extranjeros, catalogados por diferentes entrevistados como particularmente exigentes, son percibidas como presiones procedentes de un conglomerado social que empieza a valorarse críticamente. Tal y como se adelantaba en los cuadros 3 y 4 , y se explicará enseguida, este problema se ha reducido en la medida en que las urbanizaciones han pasado a perder población.

\section{IV.4. La fragmentación socio-espacial y los procesos de integración posteriores}

En este apartado se presentan las líneas discursivas básicas producidas por los políticos en relación a la cuestión de la integración social. No obstante, se ha considerado que para enmarcar esos hallazgos en un marco explicativo más adecuado resultaba interesante mostrar antes tres mapas de elaboración propia en los que se reflejan tres tipos de dinámicas municipales ilustrativas. Lo más llamativo de estos mapas es la nitidez con la que se aprecia la fragmentación: los cascos urbanos, que suelen corresponder a una o varias secciones censales de pequeño tamaño y alta densidad de población, están principalmente habitados por españoles y por los extranjeros procedentes de países con un PIB per cápita inferior al español, la proporción de extranjeros «ricos» es inferior al 25\% y en algunas ocasiones no supera ni el 5\%; sin embargo, las macrourbanizaciones periféricas se suelen agrupar en un solo distrito censal de gran extensión y con una densidad de población relativamente baja, que está ocupado en su mayoría por extranjeros «ricos», superando en cinco casos el $75 \%$ del total de residentes $(77,31 \%$ en la sección censal 0312803001 , correspondiente al diseminado de Moraira, población que a su vez pertenece al término de Teulada -ver figura 1-; 80,92\% en la sección 0309905003 y 77,05\% en la 0309905004, ambas en zonas del diseminado litoral de Orihuela; 80,22\% en la sección 0311801002 de San Fulgencio; y 82,06\% en la sección 0311301002 del municipio de Rojales). 
Figura 1

MUNICIPIO DEL LITORAL DONDE EL PORCENTAJE DE EXTRANJEROS «RICOS» SUPERAEL 75\% DE LOS RESIDENTES EN LAS SECCIONES CENSALES PERIFÉRICAS

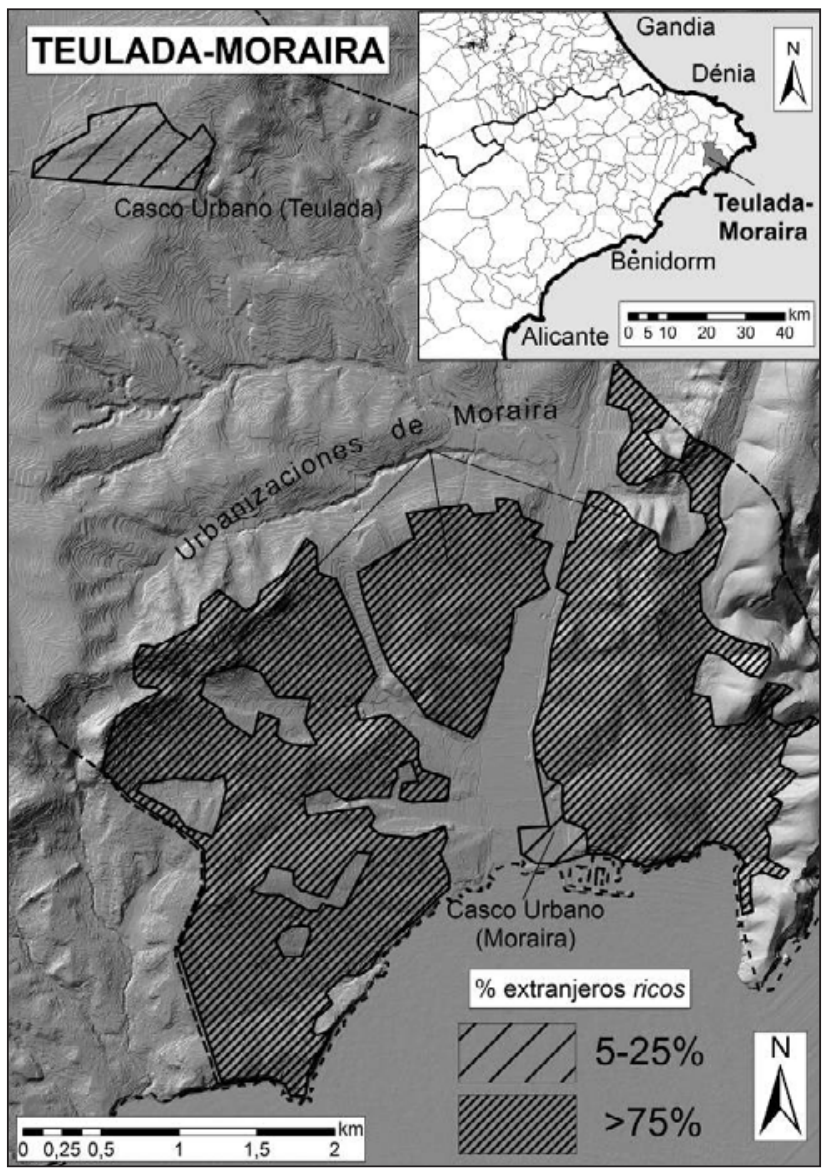

Fuente: elaboración propia a partir de los datos de secciones censales de la Estadística del Padrón Continuo (INE, 2012). Mapa de sombras del Institut Cartogràfic Valencià.

Todos estos casos corresponden a municipios del litoral, aunque en algunos del prelitoral las cifras no son muy inferiores, como en el caso de San Miguel de Salinas (figura 2), donde el porcentaje de extranjeros «ricos» es del 66,47\% en la sección 0312001002, correspondiente a todo su término salvo el antiguo casco urbano.

En los municipios del interior los porcentajes son inferiores, destacando algunos como Hondón de los Frailes (sección censal única con un 50,45\% de extranjeros «ricos»), si bien el caso de Castalla (figura 3 ) resulta más paradigmático, con un 39,36\% de extranjeros «ricos» en su sección censal 0305302002, correspondiente a todo su término salvo las secciones censales que conforman el casco urbano tradicional, donde la proporción de residentes extranjeros es inferior al $5 \%$. 


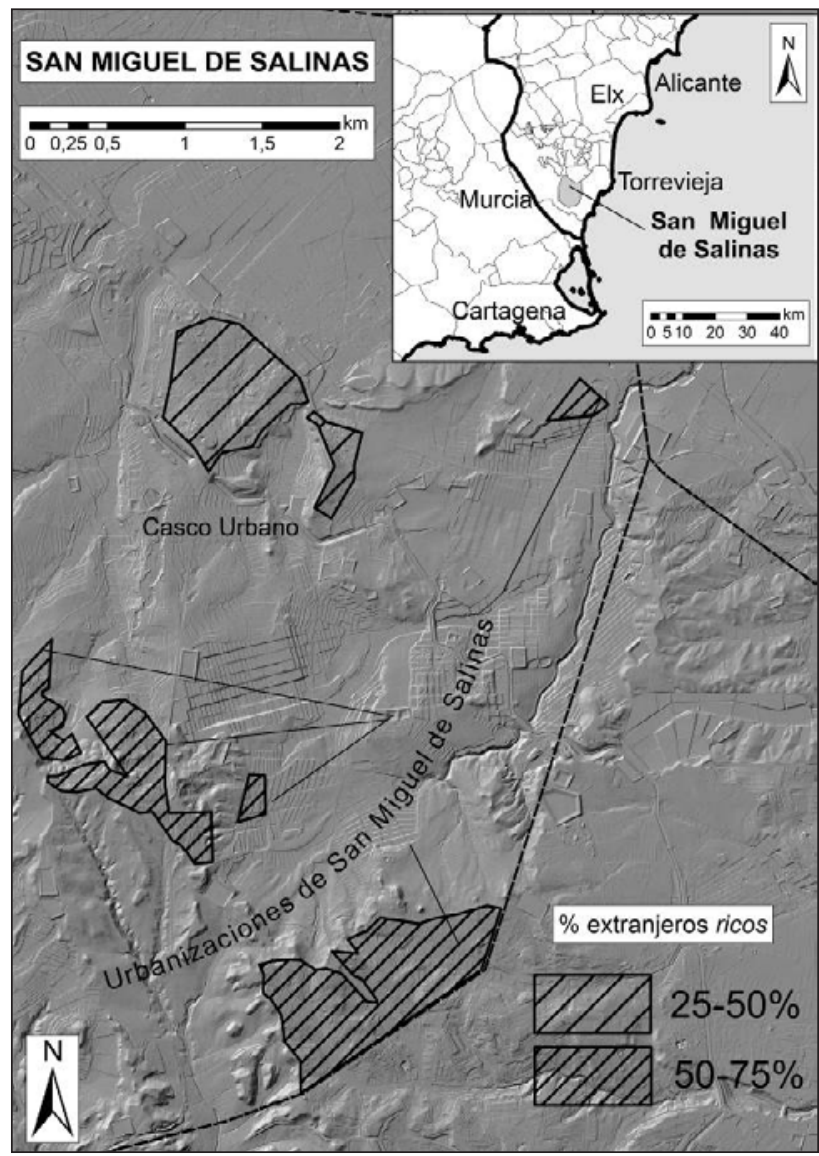

Fuente: elaboración propia a partir de los datos de secciones censales de la Estadística del Padrón Continuo (INE, 2012). Mapa de sombras del Institut Cartogràfic Valencià.

Estas cifras, con sus correspondientes mapas, muestran la dimensión que ha alcanzado el proceso de fragmentación socio-espacial en estos municipios.

El análisis de la información recogida mediante las entrevistas permite apreciar dos interpretaciones políticas a propósito de la integración social y cultural en el caso de los mayores: a) los mayores no se integran, tienden a vivir en mundos separados, principalmente porque no conocen el idioma; b) los mayores tienden a integrarse cuando se unen a asociaciones de la tercera edad en las que existen miembros de diferentes nacionalidades. Esta segunda lectura no implicaría que estas personas fueran a aprender castellano, pero sí se percibiría como un aumento en la frecuencia y densidad de las interacciones con los jubilados locales. 
Figura 3

MUNICIPIO DEL INTERIOR DONDE EL PORCENTAJE DE EXTRANJEROS «RICOS» SE ENCUENTRA ENTRE EL $25 \%$ Y EL 50\% DE LOS RESIDENTES EN LAS SECCIONES CENSALES PERIFÉRICAS

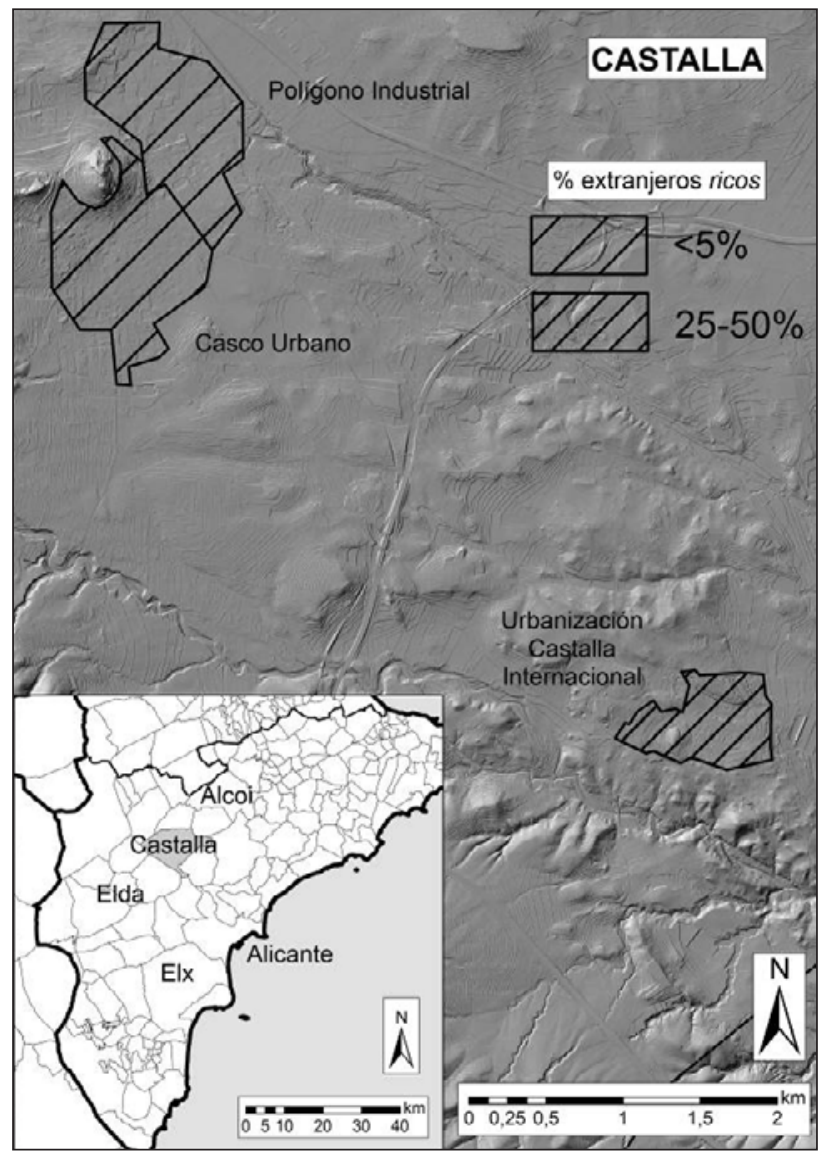

Fuente: Elaboración propia a partir de los datos de secciones censales de la Estadística del Padrón Continuo (INE, 2012). Mapa de sombras del Institut Cartogràfic Valencià.

En realidad, allí donde los extranjeros se han asentado dentro o muy cerca de los núcleos urbanos tradicionales se observan menos problemas de aislamiento (Huete y Mantecón, 2013). Ello reforzaría la idea de que el desconocimiento del idioma debería pasar a un plano menor como problema o incluso de que los extranjeros intentan aprender el idioma local.Así, tal y como puede observarse tras registrar múltiples comentarios sobre la casi total ausencia de interacción entre españoles y extranjeros -y en coherencia con los hallazgos presentados por Huete y Mantecón $(2011,2013)$ - las dificultades para la integración sociocultural procederían más bien de la existencia inicial de una fragmentación espacial: la construcción de dos espacios que, en la medida en que se encuentran geográficamente distanciados, alimentan la idea de la falta de interés recíproca por la cultura del otro. Este diagnóstico no es valorado 
por los propios políticos como algo necesariamente problemático, pero obsérvese cómo la formulación de las frases en las citas siguientes expresan tanto la indiferencia como la crítica:

«Hacen vida de jubilados, pero en España. En cuanto a quejas que yo sepa no hay ninguna, ellos están contentos, hacen sus vidas, tienen sus jardines, piscinas... se van dos o tres meses a sus países, van y vuelven, vamos, hacen sus vidas, aquí no vienen a quejarse por nada» (Tàrbena).

«No sé cómo decirte... simplemente las quejas de ellos son de escándalos, nosotros vivimos de una manera más a la calle y ellos son... están más solos, tienen su forma de estar y no se mezclan demasiado con los españoles, nosotros somos más abiertos a hacernos a cualquiera de ellos, pero los ingleses son los que menos... los holandeses sí, ellos sí que se integran, pero a los ingleses les cuesta más» (Benijófar).

La fragmentación socio-espacial es un producto de la intensa construcción de las urbanizaciones en las periferias de los viejos centros urbanos. En realidad, la separación de los espacios ocupados mayoritariamente por españoles y por los otros europeos es lo que habitualmente parece subsumir la idea del idioma como problema, y no al revés. Es decir, la separación física retroalimenta la idea de que no es necesario aprender el idioma local. La separación espacial suele estar en la base del distanciamiento sociocultural, aunque es frecuente encontrar entre los entrevistados argumentos que también intentan subrayar el modo en el que las diferencias culturales inciden en la separación entre ambos mundos. Estas diferencias culturales a menudo son subrayadas por los políticos entrevistados como un factor negativo para la convivencia, en ocasiones esgrimiendo justificaciones como las siguientes:

«Ellos tienen sus costumbres, son unos apasionados de los animales. Un animal abandonado es un dilema, el que una persona del ayuntamiento no se preocupe de coger un animal abandonado y llevarlo a un sitio a darle comida, para ellos es una tragedia. Son muy distintos, pero yo creo que poco a poco se integran, pero son muy distintos a nosotros, muy distintos, o sea, hace poco queríamos que viniera un circo y le tuvimos que decir que no, porque se pusieron en pie de guerra, porque claro como un circo suele traer un tigre que si tal, ellos dicen que un tigre en un circo eso no se puede soportar, se manifestaron todos y tuvimos que decir que no, porque ellos no soportan el maltrato animal, hay cosas que no van a cambiar nunca. No está bien lo que te voy a decir, pero aquí en el pueblo cuando un animal molesta... bueno el dueño se las apaña y hace... ipum! Para ellos eso es impensable y evidentemente cada uno tiene sus costumbres. Pero sí que cuando hacemos algo de integración, alguna fiesta para que vayan todos, que intenten hablar español, bueno se integran» (San Fulgencio).

«Son súper limpios en las calles, nosotros no. Eso a ver si se nos va pegando algo, por eso exigen mucho lo que es la imagen del pueblo, la imagen visual, exigen mucho. Nosotros a lo mejor, ves un bache y no... eso en su caso es exagerado. 
Aquí tenemos problemas con los perros, tú te subes a Montebello donde parece que la máquina pasa cada 5 minutos, a veces, vamos a hablar con el presidente y se agacha porque ha caído una hojita y la tira a la papelera» (Algorfa).

«Lo único que a veces creo que puede ser un inconveniente para ellos, son los distintos ritmos de vida que llevamos... nosotros los españoles, pues no gusta más disfrutar de más amplio horarios que ellos, ellos por ejemplo se levantan más temprano, comen y cenan más temprano, se acuestan más temprano y los españoles no, los españoles normalmente lo hacemos mucho más tarde que ellos. En un primer momento sí que notamos que para ellos era una dificultad, pero conforme ellos, se van integrando ellos saben diferenciar que cuando van a hacer un acto en común con los españoles, se va a seguir un horario, que se ajusta a nuestra cultura y que cuando no... ellos siguen el suyo» (Daya Vieja).

En el siguiente extracto se ilustra el aspecto clave comentado anteriormente: la percepción de que cuando los residentes viven en el casco urbano existe una tendencia a la integración sociocultural que contrasta con una realidad en la que lo habitual es la vida en urbanizaciones separadas:

«Cuando estaban diseminados por la huerta, veíamos como había crecido la población, pero no nos conocíamos [...] Pero claro, cuando empezó a venir población extranjera, veíamos que iban a lo suyo y no se integraban pero, a través de esos cursos y otras cosas que hemos hecho... pues ellos ya sí que hacen todo lo posible para integrarse. Dentro del casco urbano la mayoría de población extranjera sí que está integrada, con las urbanizaciones que están dentro no hay ningún problema» (Daya Vieja).

En el contexto de la crisis económica, la dinámica urbana (o, más bien, su colapso) ha provocado o bien una estabilización de la fragmentación espacial y, en consecuencia, también sociocultural, o bien un acercamiento entre los residentes y los locales.

\section{IV.5. El contexto de crisis económica}

De los discursos de los entrevistados surge una idea esencial. Al parecer, la crisis económica ha podido tener un efecto en dos sentidos contrapuestos:

Por una parte, desde el punto de vista de la movilidad espacial, la crisis produce una salida de residentes europeos de los municipios alicantinos tanto en edad laboral como de jubilados (la ilustración empírica de este efecto puede consultarse en Huete et al., 2013 y en Mantecón et al., 2013) y, al mismo tiempo, habría provocado un traslado de residentes europeos no españoles desde las urbanizaciones construidas en las periferias municipales durante las últimas dos décadas hacia los centros urbanos tradicionales. Así pues, se argumenta que la pérdida neta de población vinculada al estallido de la crisis económica se habría dejado sentir muy especialmente en las urbanizaciones periféricas y no tanto en los antiguos cascos urbanos. 
Por otra parte, y estrechamente asociado al doble efecto de movilidad señalado en el párrafo anterior, la crisis económica parece haber fomentado procesos de integración de los residentes extranjeros motivados por su creciente necesidad de comprar viviendas más baratas (ubicadas en los centros tradicionales) y, también, de contar con la ayuda de la población española, y particularmente con los servicios públicos locales, más aún si se tiene en cuenta que la población de residentes europeos no españoles se caracteriza por poseer un perfil, en su mayoría, envejecido. Una consecuencia añadida de ese perfil envejecido sería el riesgo (y el temor real) a verse inmersos en situaciones de soledad y aislamiento. La tendencia a que los residentes abandonen las urbanizaciones y compren pisos más pequeños en los cascos urbanos supondría desde este punto de vista que, en ocasiones, los problemas económicos (pérdida de poder adquisitivo de los residentes extranjeros y, a veces, auténticos procesos de empobrecimiento) han favorecido la integración espacial y, atendiendo a las cuestiones ya revisadas, de integración sociocultural.

«Cada vez más se han venido a medida que se han hecho mayores, han vendido sus chalets y se han venido a apartamentos y pisos al pueblo, eso sí que está pasando, a medida que ellos se ven más solos, que no pueden mantener su jardín y piscina, lo han vendido y se han venido al pueblo, eso sí que lo estamos viendo que está sucediendo»(Calp).

El de Calp no es un caso aislado. En Teulada-Moraira queda patente la idea de que la integración espacial implica una tendencia hacia la integración social:

«En el caso de la gente mayor ya están empezando a decidir... vuelvo a mi país, pues no, bueno, ya que estoy tengo mis amistades y toda mi vida aquí, vendo mi casa y compro una apartamento más pequeño y entonces es cuando van al casco, entonces pueden relacionarse más con los españoles» (Teulada-Moraira).

Como se indicaba, este es uno de los movimientos de los residentes valorado por los políticos entrevistados como más interesante, porque, subrayan, supone una integración espacial, y quizá sociocultural, vinculada a la crisis. En este punto de la explicación, se recuerda que la fragmentación ha sido un fenómeno vinculado a la explosión constructora y a la proliferación de urbanizaciones. Cuando los extranjeros se han asentado en urbanizaciones cercanas al casco urbano, o en el mismo núcleo, se percibe una tendencia hacia el aumento de interacciones entre los residentes españoles y los de otras nacionalidades. A su vez, los entrevistados admiten que el descenso de población en las urbanizaciones periféricas puede dejar espacios urbanos «fantasmagóricos», pero ese inconveniente quedaría en su opinión compensado por la reducción de las demandas de actuación dirigidas al ayuntamiento, con la consiguiente descarga presupuestaria.

Así pues, en general, se reconoce un discurso en virtud del cual la crisis ha tenido un impacto relevante sobre el comportamiento de los residentes europeos, sean del perfil que sean. Al respecto, los extranjeros que tenían negocios propios (gestorías, tiendas de comestibles, asistencia técnica...) habrían tenido que cerrarlos al ver reducida su clientela en la medida en que sus connacionales no consumen igual y, sobre todo, en la medida en que éstos 
salen de España. Aquí es necesario precisar que muchos locales de restauración y otros servicios estaban destinados exclusiva o casi exclusivamente a los connacionales que vivían en las urbanizaciones alejadas de los núcleos de población tradicionales (Giner, 2013). Si esas urbanizaciones reducen su número de residentes, entonces deja de haber clientes.

\section{CONCLUSIONES}

La proliferación de urbanizaciones y diseminados de «casitas» en las periferias de tantos municipios situados en las regiones mediterráneas, particularmente en la provincia de Alicante, reconfiguró la estructura urbana y social en la que se insertaban sus poblaciones y generó diversos efectos que de diferentes maneras afectaron a las dimensiones políticas, socioeconómicas, culturales y al entorno medioambiental de estas sociedades. Antes del estallido de la crisis económica, los discursos políticos hegemónicos habían caracterizado el proceso de atracción de residentes procedentes de países europeos con un PIB per cápita superior al español y de expansión inmobiliaria como «no problemático» o, sencillamente, como una fuente sostenible de producción de riqueza y, en definitiva, de progreso (Mantecón, 2008a, 2010). El colapso del sector del ladrillo y la constatada incapacidad de las instituciones políticas y económicas para generar nuevas fuentes de riqueza ha obligado a los políticos locales a realizar matizaciones.

La investigación presentada, basada en un trabajo de campo realizado en un contexto de crisis económica, sirve para comprender el modo en el que las élites políticas locales reconstruyen su sistema de justificaciones produciendo nuevas claves legitimadoras que integran los impactos de la crisis. Así, resulta interesante observar cómo, a la vez que se empiezan a reconocer aspectos críticos, se omiten posibles responsabilidades políticas y, por supuesto, cualquier reconocimiento a quienes advirtieron de los riesgos de especializar el desarrollo municipal amplificando hasta límites insospechados una economía inmobiliaria carente de planificación y disfrazada de desarrollo turístico-residencial. Los aspectos críticos que los políticos están dispuestos a reconocer se asocian a las demandas de los residentes extranjeros y a la negligencia de los promotores inmobiliarios. Con el primer grupo se adopta ahora una actitud ambivalente: por un lado, de agradecimiento por «los servicios prestados» (inversión económica en el municipio acompañada en las etapas iniciales de una ausencia de exigencias) y, por otro lado, de cierto hartazgo ante sus crecientes demandas a los respectivos consistorios y su recalcitrante reticencia a adaptarse a los ritmos de la vida local y, más allá, a la forma de ver el mundo de los españoles. Respecto al segundo grupo, el de los promotores, se establece ahora un discurso, podría decirse, orientado al distanciamiento y a la recriminación. De tal modo, las complicaciones derivadas de la nueva configuración socio-espacial del municipio, así como las posibles carencias de infraestructuras, sería el resultado de la negligencia de constructores irresponsables y, en última instancia, de los consumidores de sus productos inmobiliarios que, al fin y al cabo, decidieron voluntariamente adquirir sus propiedades en un contexto de libre mercado.

De especial interés resulta el reconocimiento de una nueva clave discursiva en virtud de la cual algunos de los entrevistados reconocen efectos positivos no previstos de la crisis económica. Paradójicamente, esos efectos positivos tienen que ver con la contribución que la crisis ha realizado a la hora de deshacer lo hecho durante los periodos de expansión, cuando 
la acción de los promotores inmobiliarios gozaba de la complicidad y el apoyo -cuando no literalmente del impulso- de los partidos políticos mayoritarios y los responsables políticos pugnaban por conseguir atraer a sus municipios al mayor número posible de residentes europeos. Así, la salida de residentes extranjeros junto al repliegue hacia los antiguos centros urbanos de los que continúan viviendo en el municipio habría fomentado nuevas formas de interacción y participación, cuestión ésta que tiende a ser valorada por los políticos muy positivamente, más aún cuando ese repliegue aligera el costoso mantenimiento de una herencia de extensas periferias que han pasado de simbolizar una particular idea de progreso a representar las contradicciones que esa idea escondía.

\section{REFERENCIAS}

CASADO, M.A. (2006): «Retiring to Spain: An Analysis of Differences among North European Nationals». Journal of Ethnic and Migration Studies, $\mathrm{n}^{\circ} 32$ (8), 1321-1339.

CONDE, F. (2009): Análisis sociológico del sistema de discursos. Madrid, CIS.

DÍAZ, F. y LOURÉS, M.L. (2008): «La globalización de los mercados inmobiliarios: su impacto sobre la Costa Blanca». Ciudad y Territorio. Estudios Territoriales, $\mathrm{n}^{\circ} \mathrm{XL}$ (155), pp. 77-92.

GINER, J. (2013): «Sorry, I'm not a tourist: migración y turismo en la Marina Alta». Papers de Turisme, $\mathrm{n}^{\circ} 54$, pp. 139-155.

HAAS, H. (2012): «Volunteering in Retirement Migration: Meanings and Functions of Charitable Activities for Older British Residents in Spain». Ageing and Society, ${ }^{\circ}$ 33, pp. 1374-1400.

HUETE, R. (2009): Turistas que llegan para quedarse. Una explicación sociológica sobre la movilidad residencial. Alicante, Universidad de Alicante.

HUETE, R. y MANTECÓN, A. (2011): «Más allá del turismo: movilidad residencial europea y nuevos núcleos urbanos». Boletín de la Asociación de Geógrafos Españoles, n 56, pp. 111-128.

HUETE, R. y MANTECÓN, A. (2012): «La participación política de los residentes británicos y alemanes en España: el caso de San Miguel de Salinas, Alicante». Revista de Geografía Norte Grande, n 51, pp. 81-93.

HUETE, R. y MANTECÓN, A. (2013): «La migración residencial de noreuropeos en España». Convergencia. Revista de Ciencias Sociales, nº 61, pp. 219-245.

HUETE, R., MANTECÓN, A., y ESTÉVEZ, J. (2013): «Challenges in Lifestyle Migration Research: Reflections and Findings about the Spanish Crisis». Mobilities, $\mathrm{n}^{\circ} 8$ (3), pp. 331-348.

INSTITUTO NACIONAL DE ESTADÍSTICA (INE) (2012): «Estadística del Padrón Continuo». Disponible en: http://www.ine.es.

JURDAO, F. (1979): España en venta: compra de suelos por extranjeros y colonización de campesinos en la Costa del Sol. Madrid, Ayuso.

MANTECÓN, A. (2008a): La experiencia del turismo. Un estudio sociológico sobre el proceso turístico-residencial. Barcelona, Icaria.

MANTECÓN, A. (2008b): «Procesos de urbanización turística. Aproximación cualitativa al contexto ideológico». Papers. Revista de Sociología, nº 89, pp. 127-144. 
MANTECÓN, A. (2010): «Tourist modernisation and social legitimation in Spain». International Journal of Tourism Research, $\mathrm{n}^{\circ} 12$ (5), pp. 617-626.

MANTECÓN, A., HUETE, R. y ESTÉVEZ, J. (2013): «El impacto de la crisis económica sobre la movilidad internacional de los residentes extranjeros en la provincia de Alicante». Revista Internacional de Estudios Migratorios, $\mathrm{n}^{\circ} 3$ (2), pp. 155-184.

MANTECÓN, A., HUETE, R. y MAZÓN, T. (2009): «Las urbanizaciones ‘europeas'. Una investigación sobre las nuevas sociedades duales en el Mediterráneo», Scripta Nova. Revista electrónica de geografía y ciencias sociales, Barcelona, Universidad de Barcelona, Vol. XIII, n 301 . Disponible en: http://www.ub.es/geocrit/sn/sn-301.htm

MARTÍ, P. y NOLASCO A. (2012): «Un caso paradigmático de sprawl: la costa de la provincia de Alicante». ACE: Architecture, City and Environment = Arquitectura, Ciudad y Entorno, no 20, pp. 173-198.

MAZÓN, T. (2006): «El turismo litoral mediterráneo: ¿políticas turísticas o desarrollo inmobiliario?», en Sociología para el futuro (Rodríguez, J.A. ed.). Barcelona, Icaria, pp. 301310.

MEMBRADO, J.C. (2013): «Sunny Spain: migrantes del sol y urbanismo expansivo en el litoral mediterráneo español». Ciudad y Territorio. Estudios Territoriales, $\mathrm{n}^{\circ}$ XLV (178), pp. 687-708.

MEMBRADO, J.C. (2014): «La costa dels jubilats: la migració nord-europea de persones retirades a la Costa Blanca». Mètode. Revista de difusió de la investigació de la Universitat de València, $\mathrm{n}^{\circ} 81$, pp. 62-71.

MUÑIZ, I., GARCÍA, M.A. y CALATAYUD, D. (2006): «Sprawl. Definición, causas y efectos». Documento de trabajo 0603, Departamento de Economía Aplicada - Universidad Autónoma de Barcelona. Disponible en: http://www.ecap.uab.es/repec/doc/wpdea0603. pdf

NASARRE, R. (1972): Las urbanizaciones particulares. La Ley del Suelo ante el fenómeno turístico. Madrid, Montecorvo.

NAVARRO, J.R., MARTÍ, P. y QUESADA, J. (2000): «Alicante: la nueva ciudad del urbanizador». Ciudad y Territorio. Estudios Territoriales, $\mathrm{n}^{\circ}$ XXXII (126), pp. 711-725.

O'REILLY, K. (2007): «Intra-European Migration and the mobility-enclosure dialectic». Sociology, $\mathrm{n}^{\circ} 41$ (2), 277-293.

REQUEJO, J. (2007): «Turistas: del concepto legal a la compleja realidad del actual panorama español». Estudios Turísticos, n 172/173, pp. 147-156.

RODRÍGUEZ, V., LARDIÉS, R. y RODRÍGUEZ, P. (2010): «Migration and the Registration of European Pensioners in Spain». Disponible en: http://www.realinstitutoelcano. org/wps/portal/web/rielcano_en/contenido?WCM_GLOBAL_CONTEXT=/elcano/ Elcano_in/Zonas_in/ARI20-2010\#.VVYA1_B1i9s

RULLÁN, O. (2012): «Urbanismo expansivo en el Estado Español: de la utopía a la realidad», en Geografía: retos ambientales y territoriales: conferencias, ponencias, relatorías, mesas redondas del XXII congreso de geógrafos españoles, (Gozálvez Pérez, V. y Marco Molina, J.A., coord.) XXII Alicante, Congreso de geógrafos españoles, pp. $165-211$.

SALVÀ, P. (2011): «El turismo residencial ¿una manifestación de nuevos turismos y nuevos comportamientos turísticos en el siglo XXI?». Cuadernos de Turismo, n 27, pp. 823-836. 
SIMÓ, C., JABBAZ, M., TORRES, F.; GINER, J. y HERZOG, B. (2005): «Asociacionismo y población extranjera en la Comunidad Valenciana». Cuadernos Electrónicos de Filosofía del Derecho, $\mathrm{n}^{\circ}$ 12, pp. 1-57. Disponible en: http://www.uv.es/CEFD/12/simo.pdf

VERA, F. (2005): «El auge de la función residencial en destinos turísticos del litoral mediterráneo: entre el crecimiento y la renovación». Papers de Turisme, $\mathrm{n}^{\circ} 37 / 38$, pp. 95-114.

\section{AGRADECIMIENTOS}

Los autores agradecen la colaboración de Saúl Mira, Jesús F. Estévez y Antoni Martínez Bernat en esta investigación, además de las valiosas sugerencias de los revisores anónimos de este artículo. 